\title{
Os benefícios da uva na saúde humana: uma revisão
}

\author{
The benefits of grape on human health: a review
}

Los beneficios de la uva en la salud humana: una revisión

\section{Resumo}

A busca por alimentos funcionais, aumenta o consumo da uva e a torna objeto de estudos científicos, tendo em vista os benefícios que pode proporcionar à saúde humana. Assim, o trabalho tem como objetivo descrever as funcionalidades atreladas ao consumo da uva (Vitis vinifera), os mecanismos de ação e a relação dos principais compostos ativos presentes na fruta. Como metodologia, foi realizada pesquisas bibliográficas nas bases de dados, Scielo, Periódicos Capes, Microsoft Academic Search, Scopus e ScienceDirect. Trata-se de uma pesquisa descritiva, com abordagens que detalham as características e especificações desde a videira, fruta (casca, polpa e sementes), subproduto, compostos bioativos, composição química e funcionalidades. Como resultado, identificou-se em quantidade elevada os compostos fenólicos, sendo os mais relevantes, os flavonoides, os estilbenos, os ácidos fenólicos e uma diversidade de taninos. Os flavonoides, com maior teor, estão presentes na semente da uva, apresentam ação antioxidante e agem na defesa das plantas contra ações do meio ambiente e animal, como: vírus, insetos, fungos, bactérias, raios UV e diminuições dos hormônios vegetais. O estilbeno, possui ação biológica e terapêutica, tais como as fitoalexinas, e em destaque o resveratrol, atuante no combate à doenças, principalmente as cardiovasculares. Já os taninos, atuam na proteção vegetal em luta com os patógenos. Conclui-se, que a uva possui diversas propriedades funcionais antioxidante, antiinflamatória, antimicrobiana e anticarcinogênica, sendo esse estudo relevante para pesquisas posteriores referente ao tema, tendo em vista os benefícios obtidos pelo consumo da fruta.

Palavras-chave: Uva; Flavonoides; Estilbenos; Taninos; Ácidos fenólicos.

\begin{abstract}
The search for functional foods increases the consumption of the grape and makes it the object of scientific studies, considering the benefits it can provide to human health. Thus, the work aims to describe the functionalities linked to the consumption of the grape (Vitis vinifera), the mechanisms of action and the relationship of the main active compounds present in the fruit. As a methodology, bibliographic research was carried out in the databases, Scielo, Capes Periodicals, Microsoft Academic Search, Scopus and ScienceDirect. It is descriptive research, with approaches that detail the characteristics and specifications from the vine, fruit (peel, pulp and seeds), by-product, bioactive compounds, chemical composition and functionalities. As a result, phenolic compounds were identified in high quantities, the most relevant being flavonoids, stilbenes, phenolic acids and a variety of tannins. Flavonoids, with a higher content, are present in the grape seed, have an antioxidant action and act in the defense of plants against environmental and animal actions, such as: viruses, insects, fungi, bacteria, UV rays and reductions in plant hormones. Stilbene has biological and therapeutic action, such as phytoalexins, and especially resveratrol, which acts in the fight against diseases, especially cardiovascular ones. The tannins, on the other hand, act in plant protection in fight with pathogens. It is concluded that the grape has several functional antioxidants, anti-inflammatory, antimicrobial and anticarcinogenic properties, and this study is relevant for further research on the subject, in view of the benefits obtained by consuming the fruit.
\end{abstract}

Keywords: Grape; Flavonoids; Stilbenes; Tannins; Phenolic acids.

\section{Resumen}

La búsqueda de alimentos funcionales incrementa el consumo de la uva y la convierte en objeto de estudios científicos, considerando los beneficios que puede aportar a la salud humana. Así, el trabajo tiene como objetivo 
describir las funcionalidades vinculadas al consumo de la uva (Vitis vinifera), los mecanismos de acción y la relación de los principales compuestos activos presentes en el fruto. Como metodología, la investigación bibliográfica se realizó en las bases de datos Scielo, Capes Periodicals, Microsoft Academic Search, Scopus y ScienceDirect. Se trata de una investigación descriptiva, con enfoques que detallan las características y especificaciones de la vid, fruto (piel, pulpa y semillas), subproducto, compuestos bioactivos, composición química y funcionalidades. Como resultado, se identificaron compuestos fenólicos en altas cantidades, siendo los más relevantes los flavonoides, estilbenos, ácidos fenólicos y una variedad de taninos. Los flavonoides, con mayor contenido, están presentes en la semilla de la uva, tienen acción antioxidante y actúan en la defensa de las plantas frente a acciones ambientales y animales, tales como: virus, insectos, hongos, bacterias, rayos UV y reducciones de hormonas vegetales. El estilbeno tiene acción biológica y terapéutica, como las fitoalexínases, y especialmente el resveratrol, que actúa en la lucha contra las enfermedades, especialmente las cardiovasculares. Los taninos, en cambio, actúan en la protección de las plantas en la lucha contra los patógenos. Se concluye que la uva tiene varias propiedades funcionales antioxidantes, antiinflamatorias, antimicrobianas y anticancerígenas, y este estudio es relevante para futuras investigaciones sobre el tema, en vista de los beneficios que se obtienen al consumir la fruta.

Palabras clave: Uva; Flavonoides; Estilbenos; Taninos; Ácidos fenólicos.

\section{Introdução}

A preocupação e consciência em torno da melhoria de qualidade de vida, faz com que se busque uma alimentação saudável, que consiste na busca por alimentos que ofereçam tanto propriedades que vão além de nutrir, quanto proteger o organismo de doenças (Freitas, Detoni, Clemente \& Oliveira, 2010).

Ainda que os alimentos forneçam nutrientes e energia fundamentais para a vida, estes só podem ser considerados funcionais se proporcionaram benefícios fisiológicos adicionais, que contribuam para a redução do risco de doenças crônicas ou otimização da saúde do indivíduo (Crowe \& Francis, 2013; Hasler, 2002; Hasler \& Brown, 2009).

Ou seja, os alimentos funcionais são alimentos, parte deles ou ingrediente, que quando consumidos, produzem efeitos benéficos pra a saúde, por suas funções nutricionais básicas e por seus efeitos metabólicos e/ou fisiológicos (Ruivo, Francisco, Oliveira \& Figueiras, 2015).

Algumas pesquisas têm se voltado para a uva (Vitis vinifera) como objeto de estudo, por ser um alimento que apresenta várias propriedades benéficas para o consumo, sendo fonte de carboidratos, importantes para o fornecimento de energia para o corpo, contém vitamina C, vitaminas do complexo B e sais minerais como ferro, cálcio e potássio (Natividade, Corrêa, Souza, Pereira \& Lima, 2013; Rizzon \& Link, 2006; Santana, 2012).

A uva é uma baga disposta em cacho, de formas variáveis podendo ser esférica, ovóide ou elipsóide, de peso e tamanho diferentes, com diversas colorações verde, branca, dourada, rosada, rubra, azulada ou preta, e, seu aroma e o sabor vão do doce ao adstringente (Gomes, 2007; Afonso, 2009 apud santos, 2013).

Trata-se de um fruto valioso, que conta com uma vasta variedade de videiras espalhadas pelo mundo, e sua distribuição para o consumo pode ser tanto em seu estado in natura ou como produtos semiprocessados, processados e ultra processados, tornando o seu valor aquisitivo ainda maior (Beres, et al., 2017).

Vale ressaltar que entre toda a produção global, cerca de $80 \%$ são atribuídas para os procedimentos de vinificação, os compostos fenólicos são retirados em parte, no sumo e no vinho, e a outra parte fica presente na casca e sementes, renomado como bagaço da uva (Vitis vinifera) (Trost, et al., 2016).

Quanto à composição química, a uva apresenta água, elevados teores de açúcares e ácidos orgânicos, que são os responsáveis por seu sabor característico, minerais como potássio, cálcio, ferro, cobre, entre outros e compostos fenólicos, os quais estão relacionados a efeitos benéficos à saúde, além de serem responsáveis pela cor e adstringência ((Natividade, Corrêa, Souza, Pereira \& Lima, 2013; Rizzon \& Link, 2006; Santana, 2012).

Entre as propriedades funcionais apresentadas pela uva estão: funções antioxidante, antiinflamatória, antimicrobiana e anticarcinogênica (Abe, Mota, Lajolo \& Genovese, 2007). Sendo, que o resveratrol, composto fenólico, apresenta um 
importante papel causando benefícios ligados ao sistema cardiovascular (Sautter et al., 2005). Além disso, as catequinas, flavonóides, antocianinas e ácidos fenólicos, exibem ação antioxidante (Anjo et al., 2004), onde os flavonoides, possuem ainda efeito vasodilatador, inibe o envelhecimento precoce e a multiplicação de células cancerosas, estimula as funções hepáticas, estimulante digestivo além de estabelecer o equilíbrio ácido-alcalino (Pala \& Toklucu, 2013). Nesse sentido, o presente trabalho tem como objetivo apresentar as funcionalidades atreladas ao consumo da uva (Vitis vinifera), descrevendo os mecanismos de ação e a relação entre estrutura e atividades dos principais compostos ativos presentes na fruta, de forma a evidenciar os benefícios apresentados por suas propriedades naturais.

\section{Metodologia}

O trabalho foi executado a partir da construção teórica do tema, por meio de pesquisas bibliográficas nas bases de dados, Scielo, Periódicos Capes, Microsoft Academic Search, Scopus e ScienceDirect, com descritores: benefícios da uva, uva e saúde, propriedades funcionais da uva, composição química da uva.

Trata-se de uma revisão integrativa, de natureza qualitativa, que traz Botelho, Cunha e Macedo (2011) como suporte metodológico no cumprimento das etapas desse trabalho.

Serão selecionados artigos e livros publicados nos últimos 28 anos. Tendo em vista a importância dos fatos mencionados e o tema abordado que detalham as características e especificações da uva (Vitis vinifera), desde a videira, fruta, subproduto, compostos bioativos, composição química, suas funcionalidades, bioatividades e antioxidantes.

Nesse sentido, foram utilizados os artigos que estivesses na íntegra, dentro do recorte temporal, nos idiomas inglês e português. E, foram excluídos os que não se enquadravam nesses quesitos e os que não estivessem alinhados aos objetivos do trabalho.

\section{Resultados e Discussão}

Uva

A Vitis vinifera é conhecida popularmente por uva, parreira, videira e vinha e se trata de um arbusto trepador. Está situada no grupo das cormófitas, sendo plantas autótrofas cuja sua nutrição é própria, divididas entre raiz, caule, gavinhas, folhas, flores, fruto e semente (Hidalgo, 1993). De origem europeia, pertencendo à família vitaceae, e sua perspectiva de vida pode variar entre 30 a 40 anos.

As inúmeras variedades de videiras existentes no nosso país se deram no decorrer da nossa colonização, com a vinda dos portugueses no ano de 1532, então houve uma distinção de classe entre os tipos de uvas (Vitis vinifera) já existentes em nosso país (Botelho \& Pires, 2009). Em seguida, após as importações, a uva predominante nas plantações era a Vitis labrusca, pois o manejo era menos complicado e a espécie mais resistente (Botelho \& Pires, 2009).

Muitos fatores podem influenciar de forma negativa quanto ao manejo de videiras, sendo alguns deles: pragas, fungos, e climática da região o que necessita de um cuidado individualizado para cada espécie, destacando a Vitis vinifera que é mais vulnerável, porém enaltecida pela sua vasta busca no comércio (Chadha \& Shikhamany, 1999).

De acordo com Botelho e Pires (2009) o surgimento de pragas, mais especificamente a filoxera, prejudicaram o plantio de uva (Vitis vinifera), pois suas mudas eram espalhadas através de estacas, e com esse ataque passaram a ser mudas enxertadas.

Segundo Chavarria e Santos (2009) essa precaução voltada ao plantio das diversas espécies de uva no Brasil, sempre necessitou de uma atenção maior quanto ao clima, o que tornou restrito às regiões Sul e Sudeste, pois seu clima temperado, beneficiava a pós safra que entrava em inércia durante o inverno. Com isso, em alguns plantios, ocorre uma antecipação na 
retirada das uvas da videira, pois para a chuva não destruir a safra, é necessário colher antes do amadurecimento (Chavarria \& Santos, 2009).

É provável que o ciclo vegatativo da videira, sofra modificações decorrentes da quantidade de calor presente na atmosfera e energia emitida pelo sol (Miele \& Mandelli, 2003). Neste contexto, quando o plantio obtém uma proteção de cobertura, o mesmo está preparado para assegurar a qualidade da plantação em qualquer época, com isso irá amenizar a perda das uvas (Vitis vinifera), trazendo benefícios econômicos para o agricultor (Schiedeck, 1999).

A videira é um vegetal que apresenta várias fases no seu desenvolvimento como apresentado na Figura 1.

Figura 1. Fases da videira.
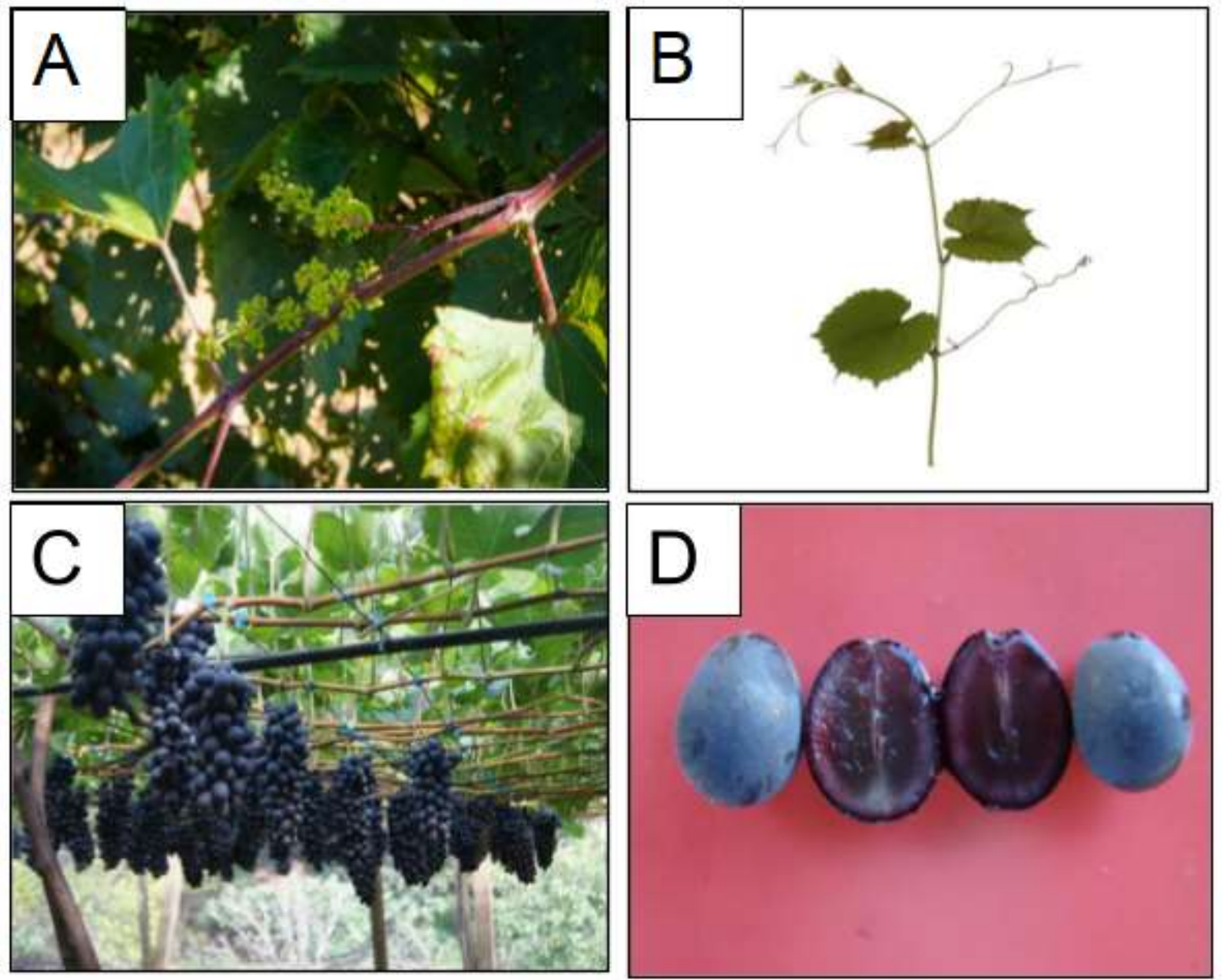

Nota: $\mathrm{A}=$ Floração da videira; $\mathrm{B}=$ Galho da videira; $\mathrm{C}=$ Frutos da videira; $\mathrm{D}=$ Partes do fruto da videira. Fonte: Adaptado de Embrapa (2012).

Os resíduos das uvas (Vitis vinifera) abrangem a casca e semente, que possuem um alto teor de composições fenólicas diversificadas (Gruz, Sousa, Torres, Freitas \& Cabral, 2013). De acordo com Rockenbach (2008), na casca da uva estão presentes em maior quantidade os flavonóides resveratrol, luteolina e kaempferol.

O peso seco do bagaço equivale a mais que a metade do peso total, ressaltando mais ainda os compostos fenólicos, sendo eles: antocianinas, ácidos hidroxicinâmicos, catequinas e flavonoides (Rockenbach, 2008). Ademais, contém valores altamente relevantes de fibra alimentar, juntamente com seu teor elevado de nutrientes (Llobera \& Cañellas, 2008).

A maior concentração encontrada na polpa da uva, são os ácidos fenólicos que variam de acordo com 80-85\%, podendo diminuir quando a fruta está madura, o que irá variar de acordo com cada cultivo específico (Arsego, 2004). Quando 
ocorre a esmagação dos grãos durante o processo da produção de vinho, os fenólicos são emanados durante este ato (Penter, 2006).

Os componentes dominantes na polpa da uva são os açúcares solúveis, porém os ácidos também têm poder predominante no sabor da fruta. Além disso, é no teor da acidez encontrado no fruto, que é capaz de conservar o alimento como os ácidos dominante na uva, ácidos málico, cítrico e tartárico (Pádua, 2018).

Dentro da polpa se encontram as sementes ou grainhas, que são as sementes pequenas, e quando a uva não possui semente, denomina-se epirena, não contendo apenas isto, possuem também o suco e mosto, que pode variar sua coloração de acordo com a safra (Kuhn, et al., 1996).

A uva pode apresentar de duas a quatro sementes (Shinagawa, 2015). O teor lipídico da semente da uva pode variar em torno de 7 a 20\% (Beveridge, Girard, Kopp \& Drover, 2005). No mais, está repleta de nutrientes, sendo eles 35\% de fibras, $11 \%$ de proteínas, $3 \%$ de minerais, $7 \%$ de água e a cerca de $29 \%$ de compostos minoritários como fitoesteróis, compostos fenólicos e tocoferóis. Contudo, os valores nutritivos variam de acordo com a atividade exercida, tais como, a prensagem para obtenção deste conteúdo (Shinagawa, 2015).

\section{Compostos ativos encontrados na uva}

Os alimentos fornecem micronutrientes e macronutrientes primordiais e possibilitam a ingestão de compostos químicos que por sua vez estão presentes em hortaliças e frutas, suas ações desempenham um papel de proteção biológica ao corpo, sendo assim benéficas a saúde humana (Carratu \& Sanzini, 2005).

As uvas (Vitis vinifera), que possuem pigmentação mais escura, tem presente em si, uma alta ação de antioxidantes e compostos fenólicos (Abe, Mota, Lajolo \& Genovese, 2007). No âmbito da vegetação, os compostos fenólicos, se encontram amplamente atribuídos a ingestão alimentar humana (Soares, 2002).

As videiras quando passam por processos de estresse, sendo eles bióticos ou abióticos, que reduzem os compostos presentes nela (Dixon e Paiva, 1995). As substâncias fenólicas da uva (Vitis Vinifera), são provenientes do metabolismo secundário, executam ações de defesa, pigmentação e atração de animais polinizadores (Yilmaz \& Toledo, 2004).

Entre as diversas classes de substâncias antioxidantes, provindas de acontecimentos naturais, os compostos fenólicos, vem sendo destaque atualmente (Soares, 2002).

O teor de compostos fenólicos na uva, se encontra em uma quantidade elevada, contudo ocorrem diversas mudanças de características, sabor e cor, sendo assim associado ao perfil de polifenólicos (Abe, Mota, Lajolo \& Genovese, 2007). Os fenólicos mais relevantes encontrados na uva (Vitis vinifera), são os flavonoides, os estilbenos, os ácidos fenólicos e uma extensa diversidade de taninos (Albuquerque \& Barbosa, 2000).

\section{Flavonoides}

Em 1930, ocorreu o primeiro isolamento de flavonoides, decorrentes de laranjas, foi julgado como um mais novo integrante do grupo das vitaminas, sendo nomeado de vitamina P, mas após outras análises, foi constatado que era um flavonoide (Machado, Nagem, Peters, Fonseca \& Oliveira, 2008).

Os flavonoides agem na defesa das plantas contra ações já esperadas do meio ambiente e animal, tais como: vírus, insetos, fungos, bactérias, raios UV e diminuições quanto aos hormônios vegetais (Zuanazzi \& Montanha, 2004 apud Rodrigues, Souza, Godinho, Ferreira \& Vila Verde, 2015). Nas uvas, os flavonoides possuem uma variação derivada dos diferentes cultivos, e respostas biológicas (Abe, Mota, Lajolo \& Genovese, 2007). 
Fatores abióticos (eventos decorrentes de ações da natureza), tais como, radiação, raios UV, épocas de seca ou chuva e substâncias nutritivas, podem interferir no metabolismo de realização destes compostos (Machado, Nagem, Peters, Fonseca \& Oliveira, 2008).

Outra ação bastante recorrente, é a poluição, que aumenta a produção no que se trata da quantidade dos metabólitos secundários, e também os flavonoides, que atuam em defesa contra os vírus, bactérias, fungos e insetos (Machado, Nagem, Peters, Fonseca \& Oliveira, 2008).

Estima-se que a dificuldade da média de consumo da substância se dá por parte da vasta diversidade de flavonoides existentes e da variedade das plantas e a ingestão alimentar humana (Clifford \& Scalbert, 2000).

Podemos afirmar que os níveis de flavonoides totais e individuais na alimentação estão ligados diretamente por fatores genéticos das espécies vegetais e condições ambientais (Machado, Nagem, Peters, Fonseca \& Oliveira, 2008).

O sistema de absorção dos flavonoides modifica de acordo com os alimentos, em razão da heterogeneidade de açúcares, e de demais substâncias funcionais relacionadas ao núcleo de flavonas (Walle, 2004).

Frequentemente os flavonoides são absorvidos durante a passagem pelo processo de deslocação dos enterócitos, depois de serem glicosilados, ou seja, convertidos em agliconas que são as glicosidases encontradas na mucosa gastrointestinal e microflora do cólon (Hollman, Van, Buysman, Van Der Gaag, \& Mengelers, 1995).

Depois de serem absorvidos, os mesmos são agrupados no intestino delgado e no fígado através da glicuronidação, sulfatação, metilação ou metabolizados, transformados em mínimos compostos fenólicos (Machado, Nagem, Peters, Fonseca \& Oliveira, 2008).

Métodos de estudos com técnicas isoladas, mostram a vasta ação dos flavonoides, mediante os sistemas biológicos, tornando evidente os efeitos antimicrobiano, antiviral, antiulcerogênico, citotóxico, antineoplásico, antioxidante, antihepatotóxico, anti-hipertensivo, hipolipidêmico, anti-inflamatório, antiplaquetário (Machado, Nagem, Peters, Fonseca \& Oliveira, 2008).

Além disso, apresentou um crescimento na permeabilidade capilar, inibição da oxidação protéica e migração de leucócitos (Pelzer, Guardia, Osvaldo, Juarez \& Guerreiro, 1998).

O grupo de flavonoides são compostos fenólicos vastamente distribuídos entre as frutas e vegetais, eles se mostram a partir das moléculas fenólicas simples até compostos altamente polimerizados (Trueba, 2003).

Possuem 13 tipos de subclasses, sendo todos exibidos em um esqueleto de hidrocarboneto do tipo C6-C3-C6 (difenilpropano) derivado do ácido shiquímico e 3 resíduos de acetato, como apresentado na Figura 2 (Trueba, 2003).

Figura 2. Estrutura básica dos flavonóides e sistema de numeração.

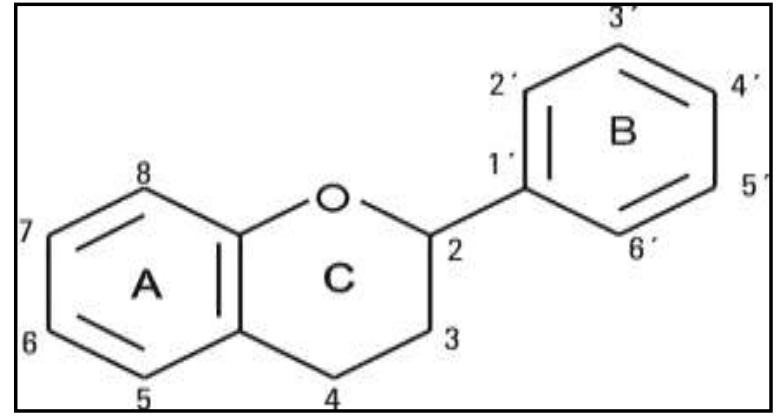

Nota: A = Núcleo flavilum. Fonte: Trueba (2003). 
As ações bioquímicas dos flavonoides e os metabólitos necessitam da estrutura química, que se diversificam com as com as trocas incluindo hidrogenação, hidroxilações, metilações, malonilações, sulfatações e glicolisações (Machado, Nagem, Peters, Fonseca \& Oliveira, 2008).

Os flavonoides são compostos fenólicos que abrangem um extenso grupo de elementos não sintetizados pelos animais (Manach, Scalbert, Rémésy \& Jiménez, 2004). E eles estão entre os grupos mais significativos dentro do reino vegetal (Yao, et al., 2004).

A catequina e epicatequina, quercetina e antocianinas, são os flavonoides encontrados na semente e casca da uva (Vitis vinífera), contendo um alto teor de antioxidantes (O'byrne, Deveraj, Grundy \& Jialal, 2002).

Existem mais de 4.000 flavonoides encontrados em fontes vegetais, em maior quantidade as seguintes classes: flavonóis, flavonas, flavanonas, catequinas, antocianinas, isoflavona, diidroflavonois, e chalconas, como apresentadas na Tabela 1 (Yao, et al., 2004).

Tabela 1. Flavonoides essenciais.

\begin{tabular}{llll}
\hline Sub-classes & Cor & $\begin{array}{l}\text { Flavonoides } \\
\text { Representativos }\end{array}$ & Fontes Alimentares \\
\hline Antocianidina & Azul, vermelho e violeta & $\begin{array}{l}\text { Cianidina } \\
\text { Catequinas, Epicatequinas } \\
\text { procianidina }\end{array}$ & $\begin{array}{l}\text { Frutas e flores } \\
\text { Maçãs, chá, cerveja, sucos } \\
\text { de uva e vinho }\end{array}$ \\
Flavanol & Incolor e amarelo & Hisperidina, Naringenina & Frutas cítricas \\
Flavona & Incolor e amarelo & Apigenina, Luteolina & $\begin{array}{l}\text { Cereais, frutas, flores e } \\
\text { vegetais } \\
\text { Flavonol }\end{array}$ \\
Amarelo claro & Amarelo claro & $\begin{array}{l}\text { Rutina } \\
\text { Cebolas, maçãs, chá, } \\
\text { tomates, trigo sarraceno }\end{array}$ & $\begin{array}{l}\text { Legumes(derivados da } \\
\text { soja) }\end{array}$ \\
\hline
\end{tabular}

Fonte: Adaptado de Acker et al. (1996).

\section{Taninos}

A classificação dos taninos é definida de acordo com a sua estrutura química, fundamentada em sua resistência ou não, consideradas na hidrolisáveis e não hidrolisáveis (Monteiro, Albuquerque, Araújo \& Amorim, 2005).

Os efeitos biológicos dos taninos podem ocorrer de duas maneiras tanto de forma inabsorvíveis, que são estruturas complexas e podem ocorrer efeitos locais na região gastrointestinal (antioxidante, eliminador de radicais, antimicrobianos, antivirais, antimutagênicos e antinutrientes) ou absorvíveis, que são estruturas de simples absorção e de baixo peso molecular, produzindo efeitos sistêmicos em vários órgãos (Monteiro, Albuquerque, Araújo \& Amorim, 2005).

Nas frutas são detectados uma grande variedade de taninos, sendo determinado os compostos fenólicos de alto peso molecular, onde ocorre o aceleramento das proteínas salivares e das cavidades orais (Rocha, et al., 2011).

As características dessas proteínas são indispensáveis para descrever a função dos taninos na proteção vegetal em luta com os patógenos e no bloqueio que se sustêm destas plantas. Eles se dividem de acordo com a sua estrutura: taninos hidrolisáveis e taninos condensados ou proantocianidinas (Efraim, Tucci, Pezóa-Garcia, Haddad \& Eberlin, 2006). De modo que são fortes inibidores de enzimas por sua complexidade em proteínas enzimáticas (Naczk \& Shahidi, 2004). 
Os taninos possuem reações com as proteínas por pontes de hidrogênios e ligações hidrofóbicas, no processo de oxidação ocorre a transformação dos taninos em quinonas formando ligações covalentes com grupos sulfidrilos da cisteína e $\varepsilon$ amino da lisina que fazem parte de grupos funcionais das proteínas (Mello \& Santos, 2001).

Os taninos são classificados a partir do formato da sua estrutura química, que são dois grupos: taninos condensados e taninos hidrolisáveis. Os hidrolisáveis são encontrados nas famílias Choripetalae das dicotiledôneas, dicotiledôneas herbáceas e lenhosas (Mello \& Santos, 2001).

Taninos condensados de forma inabsorvíveis ou pobremente digeríveis podem ser encontrados na fração de fibra alimentar de alguns alimentos. Eles têm uma atenção considerável em leguminosa e cereais, em vista dos efeitos adversos que envolvem por sabor e qualidade nutricional (Bartolomé, Jiménez-Ramsey \& Butler, 1995).

As árvores das classes, castanheiro e carvalho usadas como fonte industrial de taninos. Sendo eles taninos hidrolisáveis como mostra na Figura 3 elas dispõem um grupo poliol central (em sua maioria, é $\beta$-d- glicose, mas também o ácido quínico, outros fenóis e outros glicósidos); e hidroxilas esterificadas pelo ácido gálico sua parte fenólica (Khanbabaee \& Ree, 2001).

Figura 3. Estrutura química de taninos hidrolisáveis.

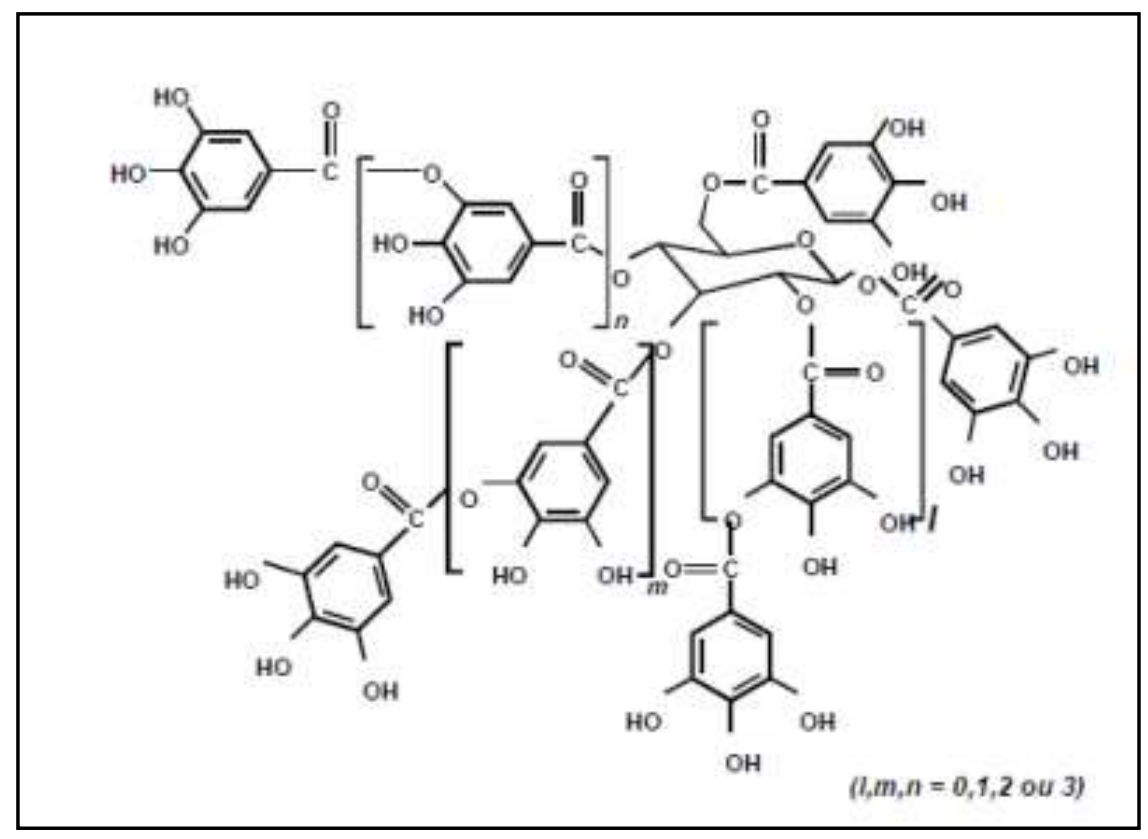

Fonte: Nakamura, Tsuji e Tonogai (2003).

Os hidrolisáveis ainda apresentam outras separações, tais como galotaninos, que possuem unidades de ácidos gálicos interligados por depsídicas, como mostra na Figura 4 alguma delas. De acordo com Clifford e Scalbert (2000) as mesmas, são bem difíceis de serem encontradas na ingestão humana, e também citam o ácido tânico, como um misto de diversos taninos gálicos. 
Figura 4. Estruturas de interligações depsídicas, formada através dos fenólicos e unidades de ácidos gálicos.

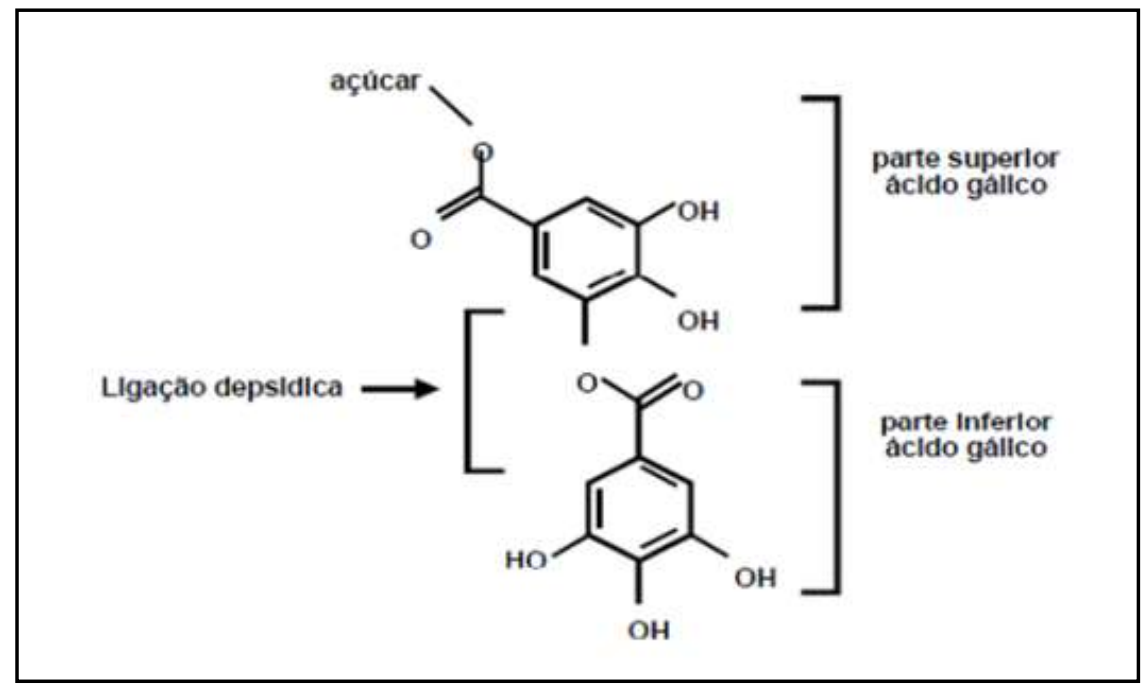

Fonte: Harvey (2001).

Os elagitaninos são moléculas que apresentam um ou dois substratos de hez-hidroxidifenil, no qual são ganhados através da junção oxidativa C-C, com dois substratos de ácido gálico adjacentes. Depois que ocorre a hidrólise ácida, das junções ésteres, acontece uma liberação de ácido elágico, os elagitaninos isolados encontrados até então são os monômeros, dímeros, trímeros e tetrâmeros (Mello \& Santos, 2001).

Os elagitaninos estão presentes apenas na alimentação humana em alguns tipos de grupos sendo eles framboesa, morango, castanha, avelã, caju e pistachio. Tais taninos são encontrados nas folhas das plantas. Também são achados nos taninos elágicos como vinhos envelhecidos em barricas de madeira de carvalho, como o resultado da difusão da madeira durante estágio de produção em barricas (Clifford \& Scalbert, 2000).

Os taninos condensados são dispostos por uma vasta família no reino vegetal, quase sempre nas plantas lenhosas, são polímeros de flavan-3-ol e/ou flavan-3-4-diol como detalha a Figura 5, (Heil, et al., 2002).

Figura 5. Estrutura química de taninos condensados.

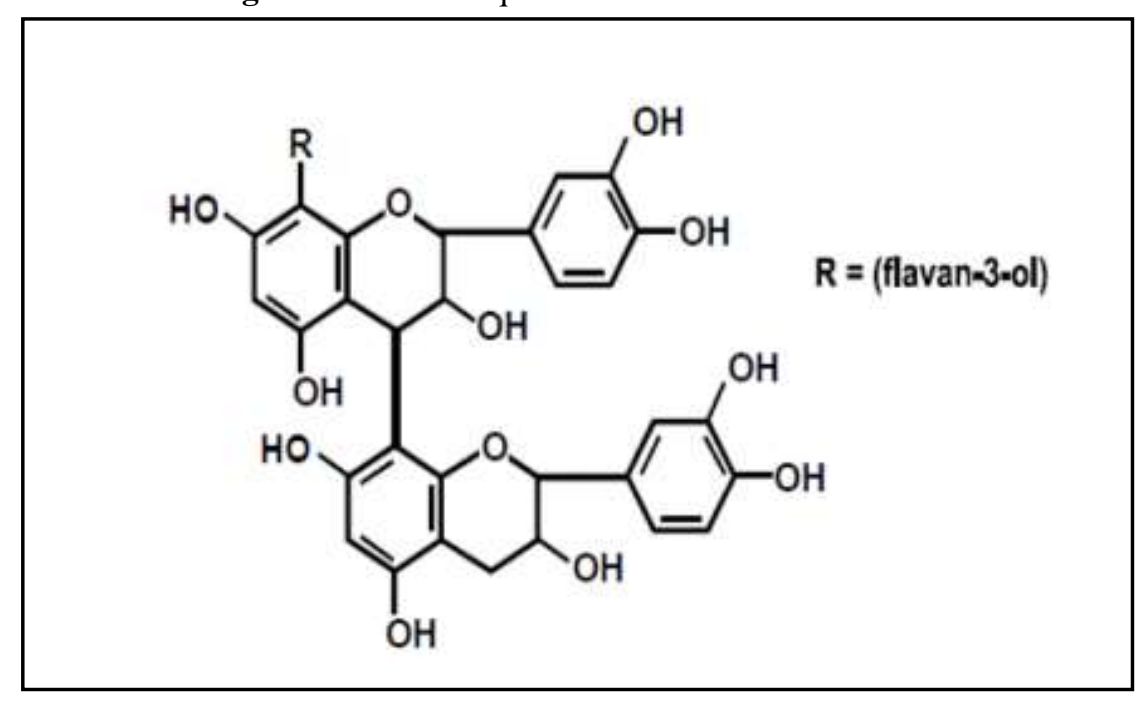

Fonte: Lekha e Lonsane (1997). 
Os mesmos conseguem ser mais encontrados na dieta humana, os taninos hidrolisáveis possuem mais uma certa dificuldade, pois os condensados apresentam mais concentrações em diversas frutas, e nos seus derivados (Clifford e Scalbert, 2000).

\section{Estilbenos}

O estilbeno não se trata de um composto de fácil acesso para ser achado, porém, os seus derivados estão presentes nas plantas, ações biológicas e terapêuticas relevantes, alguns deles são as fitoalexinas, e em destaque o resveratrol, identificado em certos tipos de uva (Nobre, Peixoto \& Monteiro, 2006).

$\mathrm{Na}$ Vitis vinífera e Vitis labrusca, se encontra uma maior quantidade de estilbenos apenas nas suas cascas. Os estilbenos apresentam um baixo peso molecular, que varia entre 210 e $270 \mathrm{~g} / \mathrm{mol}$, devido serem minúsculos compostos, ocorridos de forma natural e caracterizadas por um esqueleto de 1,2-difenil-etileno (Roupe, Remsberg, Yañez \& Davies, 2006; Chong, Potaraud \& Hugueney, 2009).

Os compostos referidos acima, são as fitoalexinas (Morales, Ros Barcelos \& Pedreno, 2000; Jeandet, et al., 2002), pois uma de suas ações, agem de forma protetora (Cos, et al., 2003). Ademais o papel do fitoalexinas, os oligômeros ou os polímeros dos estilbenos é na participação do processo de auxílio da parede celular em resposta à infecção (Chong, Potaraud \& Hugueney, 2009).

Em consequências dos metabólitos secundários eles agem como protetores nas plantas contra ataques microbianos e virais, a exibição intensa sobre a luz ultravioleta e várias outras doenças (Bavaresco, Fregoni \& Cantu, 1999). No fruto e nas folhas do hospedeiro é onde acontece a síntese e a secreção dos estilbenos (Roupe, Remsberg, Yañez \& Davies, 2006), e é guardado no interior das células em forma de glicosídeos (Ribeiro de Lima, et al, 1999).

Deste modo, depois da intimidação ambiental, o hospedeiro da planta ativa através do fenilpropanóide e pelas estruturas dos estilbenos elas são produzidas e segregadas (Roupe, Remsberg, Yañez \& Davies, 2006). Destacando-se, pois, a produção dos estilbenos específicos são dependentes de 7 grandes partes do seu hospedeiro, da região de origem e dos incentivos ambientais (Roupe, Remsberg, Yañez \& Davies, 2006).

Os acúmulos de estilbenos nas plantas, apresentam intervenções de diversos fatores, que podem ser descritos como fatores de pré-colheita, onde fica notável a importância dos fatores genéticos, as atividades agrícolas exercidas durante o plantio, o clima e exposição à luz, pragas e controle das pragas, manejo do solo, tornando uma época de colheita e maturação das plantas com menos perdas (Roupe, Remsberg, Yañez \& Davies, 2006).

Os fatores de pós-colheita, já apresentam fatores diferentes dos pré-colheita, que são o armazenamento e os processos industriais (Benbrook, 2005).

As respostas de defesa constitutivas e induzidas são devido aos elevados teores de estilbenos que pré- existem em algumas plantas que são sintetizadas após um ataque microbiano (Chong, Potaraud \& Hugueney, 2009). Sendo assim, a firmeza dos agentes patogênicos que conduz a estes tipos de resposta de defesa (Chong, Potaraud \& Hugueney, 2009).

Encontra-se diversos tipos de estilbenos reconhecidos e classificados. No entanto, vários estilbenos seguem à espera por identificações (Roupe, Remsberg, Yañez \& Davies, 2006).

Os estilbenos presentes nas plantas, são advindos da unidade básica do trans-resveratrol (3,5,4-tri-hidroxi-transestilbeno), apesar das demais estruturas serem identificadas nas famílias plantas particulares (Chong, Potaraud \& Hugueney, 2009).

Os estilbenos ciclizados como está exibido na Figura 6 é uma estrutura fenantreno que exibe uma atividade antioxidante bem mais forte que as dos compostos não-ciclizados correspondentes (Chong, Potaraud \& Hugueney, 2009). 
Figura 6. Estrutura química de fenantreno, com numeração respectiva.

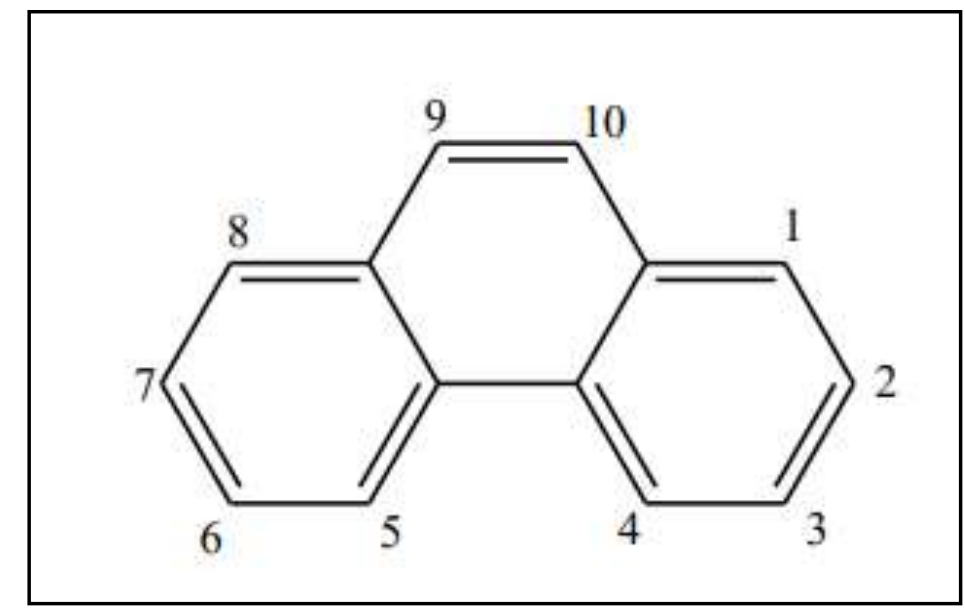

Fonte: Matias (2012).

Como dito anteriormente, uma grande classe de estilbenos presentes nas plantas, são advindos da unidade básica do trans-resveratrol, abaixo a Figura 7 detalha sua estrutura química (Chong, Potaraud \& Hugueney, 2009).

Figura 7. Estrutura química do trans-resveratrol.

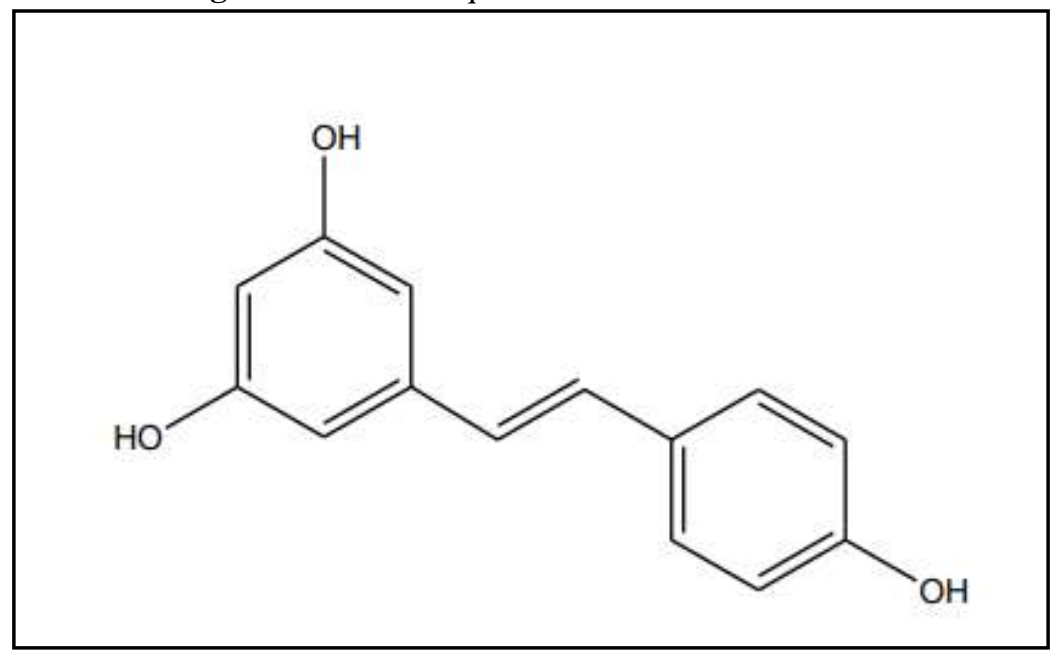

Fonte: Matias (2012).

O trans-resveratrol é considerado o estilbeno em destaque nos estudos atuais, mas isto não o torna único, também existem demais classes, como o trans-piceide conhecido como glicosídeo (Kerem, Bilkis \& Flaishman,2006), a astringina, o piceatanol, o resveratrolósido, o trans-pteroestilbeno e a rapontina todos presentes no reino vegetal (Chong, Potaraud \& Hugueney, 2009).

\section{Ácidos fenólicos}

Os ácidos fenólicos são separados por duas classes, derivados de ácidos benzóico e ácido cinâmico, o baixo consumo de hidroxibenzóicos se dá por conta da escassez nos vegetais já o hidroxicinâmicos é encontrado em abundância em diversos alimentos e bebidas (Oliveira \& Bastos, 2011). 
O primeiro grupo são os ácidos benzóicos, sendo ele o que tem sete átomos de carbono (C6-C1) e os demais que são os ácidos fenólicos mais simples que podem ser achados na natureza, como demonstra as fórmulas exibidas na Figura 8.

Figura 8. Estrutura química dos ácidos benzóicos,

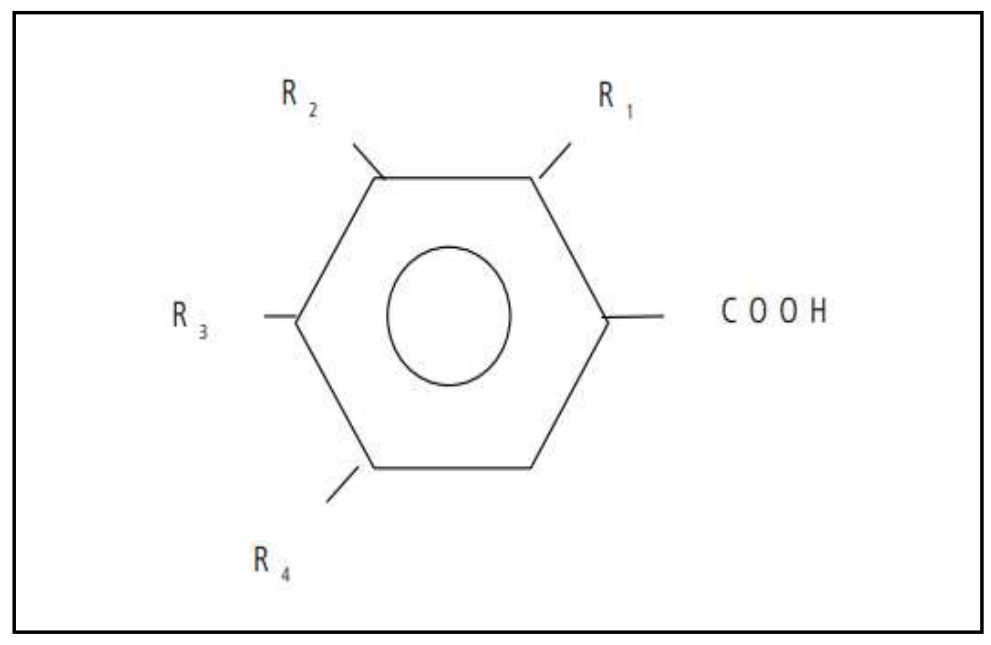

Fonte: Soares (2002).

Provindos dos ácidos hidroxibenzóicos, ressaltam-se os ácidos salicílico, gálico, elágico, protocatéico e vanílico, que podem ser achados em morango, uva, laranja, limão e tangerina (Belitz \& Grosch, 2004).

Em seguida observamos na Figura 9 que o segundo grupo é constituído por ácido cinâmicos, que apresentam nove átomos de carbono (C6 -C3), sendo quatro os mais habituais achados no reino vegetal, como apresentado na Figura 10.

Figura 9. Estrutura química dos principais ácidos cinâmicos.

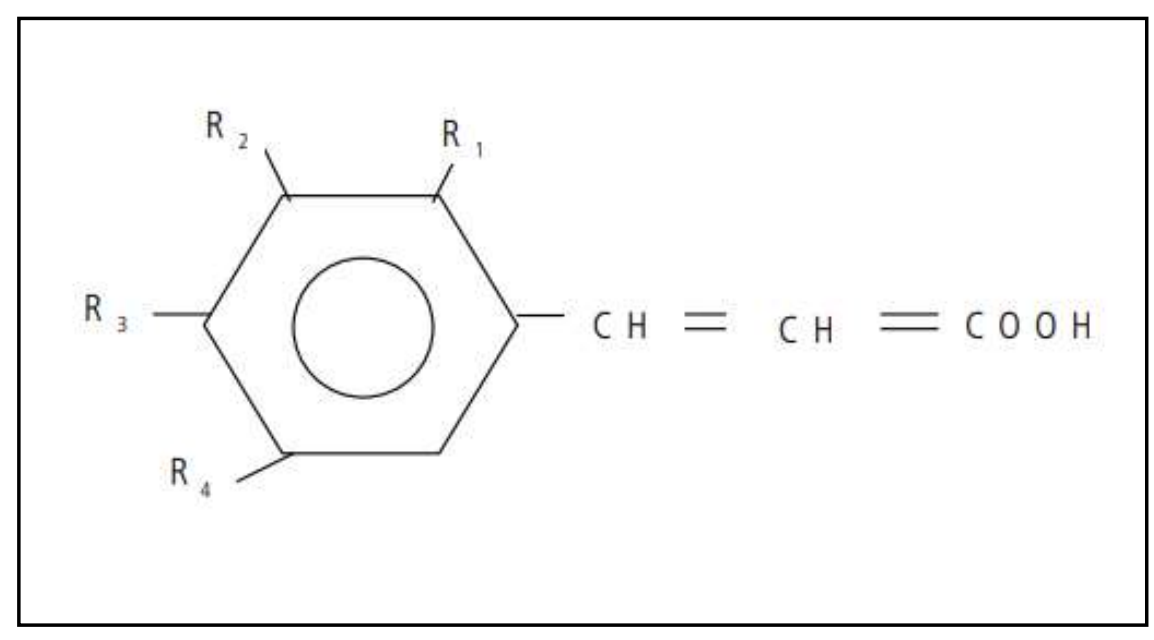

Fonte: Soares (2002). 
Figura 10. Exemplos de ácidos hidroxicinâmicos.

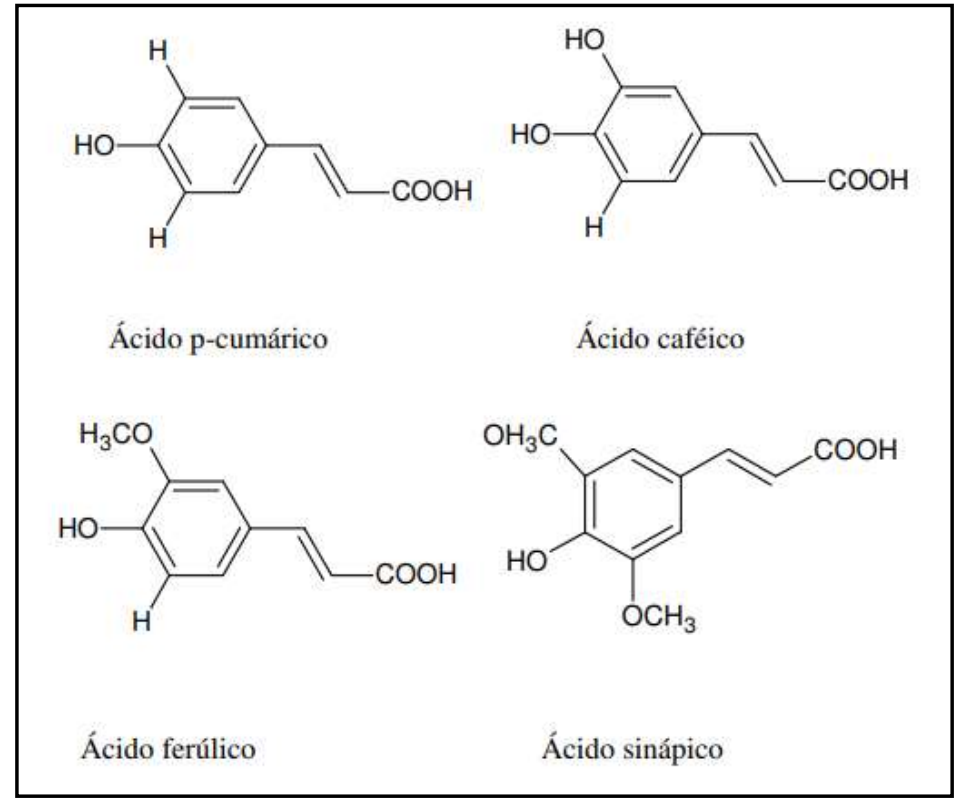

Fonte: Balasundram, Sundram e Samman (2006).

Oriundo dos ácidos hidroxicinâmicos são os ésteres dos ácidos caféico, cumárico e ferúlico, que encontra-se nos alimentos como a maçã, pêra, cereja e damasco (Belitz \& Grosch,2004).

Os ácidos fenólicos, podem ser exibidos tanto em sua estrutura química natural, como em ligações entre si ou juntamente com outros compostos (Soares, 2002).

A ação antioxidativa dos ácidos fenólicos e dos seus oriundos é variável aos números e posições dos grupos hidroxilo que estão ligados ao anel aromático, sendo seu local de ligação e sua posição relativamente aos grupos hidroxilo no anel aromático, assim como a natureza dos substituintes (Neves, 2015).

Todos os compostos citados apresentam funcionalidades comprovadas, da mesma forma essas bioatividades estão diretamente ligadas ao consumo regular da uva assim como dos produtos produzidos a partir da mesma.

\section{Funcionalidades atreladas ao consumo da uva}

No ano de 2004, a American Dietetic Association, nos seus arquivos de sobre alimentos funcionais, relatou a relevância dos subprodutos da uva tais como: vinho tinto e suco de uva foram comprovados cientificamente como ativos ao que se trata da agregação plaquetária em ensaios in vitro, in vivo e em estudos epidemiológicos (Hasler, 2004).

Pode-se afirmar que além dos alimentos funcionais caracterizar uma forma de nutrir o corpo humano ele proporciona inúmeras vantagens a quem ingere, por exemplo a modulação do sistema fisiológico e, por esse motivo o bem estar, saúde e redução dos riscos de futuras doenças (Anjo et al., 2004).

Houve, nesse sentido, um crescimento ao que se trata de fontes dietéticas apropriadas de compostos fenólicos antioxidantes. As uvas encontram-se dentro dos frutos ingeridos em maiores quantidades globais, tanto processados ou innatura, apresentando vastas fontes de compostos fenólicos (Manach, Scalbert, Rémésy \& Jiménez, 2004).

O hábito de ingestão de produtos naturais como forma de tratamento para patologias, é uma ação frequente de longas datas, decorrente dos compostos ofertados nos produtos, fornecerem pouca toxicidade mesmo que a administração seja em doses altas (Oliveira, 2010). 
O consumo do extrato de uva e seus derivados são benéficos, uma vez que seus antioxidadantes tem propriedades anticancerígenas (Çetin \& Sa dýç, 2009; Xia, Fang, Jun \& Bin, 2010). Enquanto o subproduto final, vinho, proporciona uma melhoria geral de saúde e atua de forma preventiva e na diminuição de doenças cardiovasculares (Yoo, Saliba \& Prenzler, 2010).

$\mathrm{Na}$ casca e nas sementes da uva, estão presentes os compostos secundários que possuem um importante papel fisiológico e metabólico, como crescimento, reprodução e defesa a radiação e ataque de patógenos, e, quando adicionados à dieta humana apresentam propriedades bioativas. Já a semente, a raiz, a videira e a folha da mesma, tem potencial de ação para aplicações medicinais. O extrato da semente e seus efeitos benéficos sobre os seres vivos, ganham uma atenção maior no que se diz respeito ao reaproveitamento das sementes das uvas (Unusan, 2020).

Como já exposto, os compostos fenólicos, bem como seus derivados possuem propriedades antioxidantes que são associados a inúmeros benefícios à saúde, dentre eles estão a ação antiinflamatória, anticarcinogênica, antimicrobiana, e redução do risco de desenvolvimento de doenças crônicas como aterosclerose, diabetes, hipertensão, doenças neurodegenerativas e Alzheimer (Balasundram, Sundram \& Samman, 2009; Pandey \& Risvi, 2009; Haas et al., 2018; Silva et al., 2019; apud Nied, 2019).

Ressalta-se ainda, que os compostos fenólicos encontrados na uva além da sua relevância nos aspectos do vinho como a cor, sabor e corpo, refere-se também aos resultados positivos para a saúde, com ingestão moderada (López-Miranda, et al., 2016). Exercem atos de proteção celular fundamental, que estão aptos para atuar no sequestro ou inibição de inúmeras classes de oxigênio reativo, transferência de elétrons para radicais livres, ativação de enzimas antioxidantes e inibição de enzimas oxidases (Dumitriu, Peinado, Peinado \& de Lerma, 2015).

Com isso, realizam ações de prevenção do estresse oxidativo, deixando claro que seja uma possível causa de diversas doenças, tais como: arteriosclerose, diabetes e doenças neurodegenerativas (Asadi, et al., 2010).

As antocianinas em um contexto farmacológico são consideravelmente relevantes para os agenciadores antioxidantes captadores de radicais livres, isso porque há redução na mortalidade em consequência de doenças coronárias na população humana que ingerem algum tipo de alimento incluindo flavonoides em sua alimentação, por exemplo a uva e o seu subproduto final. Assim sendo, é parcialmente explicada a inibição oxidativa da fração do colesterol LDL e por sua diminuição na incorporação plaquetária definida pelas ações dos flavonoides (Cook \& Samman, 1996).

A vitamina $\mathrm{C}$ é considerada antioxidantes eficientes na fisiopatologia de várias doenças crônicas e deve ser adquirida a partir de fontes alimentares, tendo em vista que os seres humanos são incapazes de sintetizá-la (Grosso et al., 2013).

A vitamina $\mathrm{C}$ pode ser encontrada nas uvas e são responsáveis pela promoção que atua na proteção de espécies reativas que são compostas no período de fotossíntese e de respiração, situada no desenvolvimento celular, atuando como ajuizador das mais importantes enzimas na síntese de antocianina e os outros metabólitos secundários (Soares,2002).

Efetivamente os estilbenos é um composto de importância por seu resultado modulador do metabolismo dos lipídios e sua inibição as oxidações das lipoproteínas de baixa densidade e incorporação das plaquetas, esta ocorrência está relacionada a formação das plaquetas de ateroma. De modo que, o fitoestrógeno e resveratrol atuam na proteção do sistema cardiovascular, e também com as ações antiinflamatórias e anticancerígenas (Frémont, 2000).

O resveratrol, a quercetina e a catequina são os principais compostos fenólicos presentes nas uvas e no vinho que levam a uma melhoria da saúde (Çetin \& Saðdýç, 2009). Cabe ainda ressaltar que o resveratrol é um composto em constante estudo, devido suas propriedades antiinflamatórias, antioxidantes e antifadiga, prevenir e diminuir o progresso de doenças, cardiovasculares, neurodegenerativas, metabólicas, cancerígenas e aumento da longevidade.

Já a catequina é um antioxidante eficaz na neutralização de radicais livres, e seu consumo se relaciona com os efeitos positivos, que incluem uma melhor atividade antioxidante, efeito antidiabético e a capacidade de diminuir os níveis de 
triglicerídeos no sangue, melhorando o metabolismo anormal de LDL (Ochiai, Jiar, Cai, Yamaguchi \& Yamamoto, 2015; Singh, Siddiqui, Abd, Mukhtar \& Ahmad, 2016).

A propriedade antioxidante da catequina é semelhante à da vitamina $\mathrm{C}$, uma vez que protegem o organismo de algumas doenças, reduzindo a taxa de colesterol total e aumentando os níveis de colesterol HDL (Ochiai, Jiar, Cai, Yamaguchi \& Yamamoto, 2015; Singh, Siddiqui, Abd, Mukhtar \& Ahmad, 2016).

Assim, vale ressaltar que os compostos e propriedades presentes na uva, apresentam proveito para o consumidor e para as indústrias alimentícias, possibilitando uma necessidade prioritária de pesquisa na área de nutrição e tecnologia de alimento. O que significa que, devido as principais funções de prevenção de doenças e de melhoria da saúde, há um potencial promissor nas indústrias alimentar e farmacêutica, que utilizam estes compostos fenólicos como ingredientes de alimentos funcionais (Xia, Fang, Jun \& Bin, 2010).

\section{Considerações Finais}

A compreensão da necessidade de melhoria da qualidade de vida faz com que as pessoas busquem cada vez mais alimentos funcionais, que atendam a parte nutricional alimentar, efeitos metabólicos e ainda auxilie no combate a doenças.

Com o avanço em estudos, a uva tem se mostrado evidente nesse contexto, tendo em vista propriedades funcionais antioxidante, antiinflamatória, antimicrobiana e anticarcinogênica apresentadas na composição da fruta, trazendo benefícios atrelados ao seu consumo.

Esse trabalho apresentou a uva (Vitis vinifera) como objeto de estudo, demonstrando de forma aprofundada os compostos ativos encontrados, bem como aspectos relevantes que vão desde a videira, o fruto, suas características e propriedades relevantes para a compreensão do tema.

Nesse sentido, verificou-se que, entre todos os compostos fenólicos, os flavonoides, apresentam um maior teor, existente na semente da uva, apresentando uma forte ação antioxidante. A literatura indica ainda a grande importância do resveratrol no combate à várias doenças, sendo em sua maioria as cardiovasculares.

Assim, cabe ressaltar a importância desse trabalho como base para pesquisas posteriores que beneficie e agregue conhecimento acerca da abordagem realizada, tendo em vista os benefícios obtidos pelo consumo da uva e por ser uma fruta conhecida e de fácil acesso aos consumidores.

E tendo em vista que não há o conhecimento das funcionalidades da uva pela população em geral, fica como sugestão para trabalhos futuros, desenvolver meios de facilitação de informação sobre a fruta, de forma a evidenciar no cotidiano das pessoas os benefícios da ingestão da uva para a saúde humana a longo prazo, bem como estudos que tragam dados estatísticos, comparando a saúde dos consumidores e não consumidores da fruta em sua dieta regular, como forma de verificar os ganhos adquiridos pelo consumo da uva.

\section{Referências}

Abe, L. T., Mota, R. V., Lajolo, F. M. \& Genovese, M. I. (2007). Compostos fenólicos e capacidade antioxidante de cultivares de uvas Vitis labrusca L. e Vitis vinifera L. Food Science and Technology, 27(2), 394-400. https://www.scielo.br/pdf/cta/v27n2/31.pdf.

Albuquerque, R. H. \& Barbosa, G. N. (2008). Polifenóis em vinhos tintos: fatores envolvidos, propriedades funcionais e biodisponibilidade Revista Iberoamericana de Tecnología Postcosecha, 9(2), 93-105. http://www.redalyc.org/articulo.oa?id=81315076002

Ambrósio, C. L. B, Campos, F. A. C. S. \& Faro, Z. P. D. (2006). Carotenóides como alternativa contra a hipovitaminose A. Revista de Nutrição, 19(2), 233243. https://doi.org/10.1590/S1415-52732006000200010

Anjo, D. L. C. (2004). Alimentos funcionais em angiologia e cirurgia vascular. Jornal Vascular Brasileiro, 3(2), 145- 154. https://www.jvascbras.org/article/5e1f5f740e88256a3dd8495a 
Anjo, J, B., Moreira, A. N., Teixeira, A. H. C., Dantas, B. F., Faria, C. M. B., Silva, D. J., Moreira, F. R. B., Haji, F. N. P., Costa, F. F., Alencar, J. A., Araújo, J. L. P., Soares, J. M., Choudhury, M. M., Leão, P. C. S., Silva, P. C. G., Correia, R. C., Tavares, S. C. C. H., Costa, T. S. \& Alburqueque, T. C. S. (2004). Cultivo da Videira. https://www.infoteca.cnptia.embrapa.br/infoteca/bitstream/doc/156149/1/Cultivodavideira32070.pdf.

Arsego, J. (2004). Composição polifenólica de vinhos Bordô, Isabel, Seyve Villard e Niágara Branca, produzidos no Alto Vale do Rio do Peixe-SC. https://core.ac.uk/download/pdf/30369062.pdf.

Asadi, S., Ahmadiani, A., Esmaeili, M. A., Sonboli, A., Ansari, N. \& Khodagholi, F. (2010). In vitro antioxidant activities and an investigation of neuroprotection by six Salvia species from Iran: A comparative study. Food and Chemical Toxicology, 48(5), 1341-1349. 711 https://doi.org/10.1016/j.fct.2010.02.035

Bartolomé, B., Jiménez-Ramsey, L. M. \& Butler, L. G. (1995). Nature of the condensed tannins present in the fibre fractions in foods. Food Chemistry, 53, 357-362, 1995. https://doi.org/10.1016/0308-8146(95)99827-M

Bavaresco, L., Fregoni, C. \& Cantu, E. (1999). Stilbene Compounds: From the Grapevine to Wine. Drugs Exp Clin Res., 25, 57-63. https://pubmed.ncbi.nlm.nih.gov/10370866/

Belitz, H. D. \& Grosch, W. (2004). Food chemistry. New York: Springer Verlag, 774.

Benbrook, C. M. (2005). Elevating Antioxidant Levels in Food through Organic Farming and Food Processing. The Organic Center. http://www.organiccenter.org/Antioxidant_SSR.pdf

Bender, A., Luvielmo, M., Loureiro, B., Speroni, C., Boligon, A., Silva, L. \& Penna, N. (2016). Obtenção e caracterização de farinha de casca de uva e sua utilização em snack extrusado. https://doi.org/10.1590/1981-6723.1016

Beres, C., Costa, G. N. S., Cabezudo, I., Silva; James, N. K., Teles, A. S. C., Cruz, A. P. G., Mellinger-Silva, C., Tonon, R. V., Cabral, L. M. C. \& Freitas, S. P. (2017). Towards integral utilization of grape pomace from winemaking process: a review. Waste Management. 68, 581-594. https://doi.org/ 10.1016/j.wasman.2017.07.017

Beveridge, T. H. J., Girard, B., Kopp, T. \& Drover, J. C. G. (2005). Yield and composition of grape seed oil extracted bysupercritical carbono dioxide and petroleum ether: varietal effects. Journal of agricuture and food chemistry, 53(5), 1799-1804. https://doi.org/10.1021/jf040295q

Bortolozo, E. Q. \& Quadros, M. H. R. (2007). Aplicação de inulina e sucralose em iogurte. Revista Brasileira de Tecnologia Agroindustrial, 1(1), 37-47. http://dx.doi.org/10.3895/S1981-36862007000100004

Botelho, L. L. R., Cunha, C. C. de A. \& Macedo, M. (2011). O método da revisão integrativa nos estudos organizacionais. Gestão E Sociedade, Belo Horizonte-MG.121-136. Maio/Agosto. https://doi.org/10.21171/ges.v5i11.1220

Botelho, R. \& Pires, E. (2009). Viticultura como opção de desenvolvimento para os campos gerais https://pitangui.uepg.br/departamentos/defito/labiovegetal/Viticultura.pdf. N achei

Caldeira, V., Guimarães, S., Freitas, S. \& Nassur, R. (2018). Avaliação da manutenção da qualidade de uvas passa brs vitória após aplicação de pré-tratamento químico. https://doi.org/10.18677/EnciBio_2018A13

Cantos, E., Espín, J. C. \& Tomás-Barberán, F. A. (2002). Varietal diferences among the polyphenol profiles of seven table grape cultivars studied by LCDAD-MS-MS. J. Agric. Food Chem.,50, 5691-5696. https://doi.org/10.1021/jf0204102

Carratu, E. \& Sanzini, E. (2005). Sostanze biologicamente attive presenti negli alimenti di origine vegetable. Annali dell'Istituto Superiore di Sanita, 41(1),716. https://www.iss.it/documents/20126/955767/4117.1121684384.pdf/b6630f00-93f7-59e8-857a-9ddcc3af3059?t=1575579910720

Castejon, F. V. (2011). Taninos e saponinas. Seminário apresentado junto à disciplina Seminários Aplicados do Programa de Pós-Graduação-Universidade Federal de Góias, 30, 1292-1298. https://files.cercomp.ufg.br/weby/up/67/o/semi2011_Fernanda_Castejon_1c.pdf.

Chadha, K. L. \& Shikhamany, S. D. (1999). The grape: improvement, production and post-harvest management. http://www.mph.net.in/The_Grape.asp

Chavarria, G. \& Santos, H. (2009). Manejo de videiras sob cultivo protegido: revisão bibliográfica. Ciência Rural, 39(6). https://www.scielo.br/pdf/cr/v39n6/a216cr1456.pdf.

Chavarria, G. \& Santos, H. P. (2009). Grapevines management under protected cultivation. Cienc. Rural,39 (6). https://doi.org/10.1590/S010384782009005000104

Chong, J., Poutaraud, A. \& Hugueney, P. (2009). Metabolism and roles of stilbenes in plants. Plant Science, 177, 143-155. https://www.researchgate.net/publication/223350386_Metabolism_and_roles_of_stilbenes_in_plants

Clifford, M. N. \& Scalbert, A. (2000). Ellagitannins - nature, occurrence and dietary burden. Journal of the Science of Food and Agriculture, 80, 1118-1125. http://onlinelibrary.wiley.com/doi/10.1002/(SICI)1097-0010(20000515)80:7\%3C1118::AID JSFA570\%3E3.0.CO;2-9/abstract.

Cook, N. C. \& Samman, S. (1996). Flavonoids-Chemistry, Metabolism, Cardioprotective Effects, and Dietary Sources. The Journal of Nutritional Biochemistry, 7, 66-76. https://doi.org/10.1016/S0955-2863(95)00168-9

Crowe, K. \& Francis, C. (2013). Position of the Academy of Nutrition and Dietetics: Functional Foods. Journal of the Academy of Nutrition and Dietetics, 113(8), 1096- 1103. https://doi.org/doi: 10.1016/j.jand.2013.06.002.

Çetin, A. \& Sa dýç, O. (2009); “A concise review: antioxidant effects and bioactive constituents of grape”. Erciyes Medical Journal, 31, 369-375. https://web.a.ebscohost.com/abstract?direct=true \&profile=ehost\&scope=site \&authtype=crawler\&jrnl=1300199X\&AN=46036786\&h=rcm1 sysCD58N7eNMp 
39SFG8v6jPmjMWYvnw6esq5PJ6NOnsVpCfY7dxo7yRZIQV5tw8DVeoxmbw8poOFxGBiRQ\%3d\%3d\&crl=c\&resultNs=AdminWebAuth\&resultLocal=Er rCrlNotAuth\&crlhashurl=login.aspx\%3fdirect\%3dtrue\%26profile\%3dehost\%26scope\%3dsite\%26authtype\%3dcrawler\%26jrnl\%3d1300199X\%26AN\%3d460 36786

Debastiani, G., Leite, A. C., Weiber Junior, C. A. \& Boelhouwer, D. I. (2015). Cultura da uva, produção e comercialização de vinhos no brasil: origem, realidades e desafios. Revista Cesumar-Ciências Humanas e Sociais Aplicadas, 20(2), 471-485. https://periodicos.unicesumar.edu.br/index.php/revcesumar/article/view/4395.

Dixon, R. A. \& Paiva, N. L. (1995). Stress-induced phenylpropanoid metabolism, Plant Cell, 7, 1085-1097. https://www.ncbi.nlm.nih.gov/pmc/articles/PMC160915/

Dumitriu, D., Peinado, R. A., Peinado, J., \& de Lerma, N. L. (2015). Grape pomace extract improves the in vitro and in vivo antioxidant properties of wines from sun light dried Pedro Ximénez grapes. Journal of Functional Foods, 17, 380-387. https://doi.org/10.1016/j.jff.2015.06.003

Efraim, P., Tucci, M. L., Pezoa-Gárcia, N. H., Haddad, R. \& Eberlin, M. N. (2006). Teores de compostos fenólicos de sementes de cacaueiro de diferentes genótipos. Brazilian Journal of Food Technology, 9(4), 229-236.

Francisco, A., Tomás-Barberán, F. A., Michael, N. \& Clifford, M. N. (2000). Flavanones, chalcones and dihydrochalcones - nature, occurrence and dietary burden. https://doi.org/10.1002/(SICI)1097-0010(20000515)80:7\%3C1073::AID-JSFA568\%3E3.0.CO;2-B

Freitas, A. A., Detoni, A. M., Clemente, E. \& Oliveira, C. C. (2010). Determinação de resveratrol e características químicas em sucos de uvas produzidas em sistemas orgânico e convencional. Revista Ceres. 57(1), 1-5. https://doi.org/10.1590/S0034-737X2010000100001

Frémont, L. (2000). Biological effects of resveratrol. Life sciences, 66(8), 663-673. https://doi.org/10.1016/S0024-3205(99)00410-5.

Frèmont, L. (2000). Minireview. Biological effects of resveratrol. Life Sciences, 66(8), 663 - 673. http://dx.doi.org/10.1016/S0024-3205(99)00410-5

Grosso, G., Bei, R., Mistretta, A., Marventano, S., Calabrese, G., Masuelli, L., Giganti M., Modesti, A., Galvano, F. \& Gazzolo, D. (2013). Effects of vitamin C on health: a review of evidence. Front. Biosci, 1(18), 1017-1029. https://doi.org/10.2741/4160

Gruz, A. P. G., Sousa, C. G. S., Torres, A. G., Freitas, S. P. \& Cabral, L. M. C. (2013). Recuperação de compostos bioativos a partir do bagaço de uva, Revista Brasileira de Fruticultura, 35(4), 1147-1157. https://doi.org/10.1590/S0100-29452013000400026.

Hasler, C. (2002). Functional foods: benefits, concerns and challenges - A position paper from the American Council on science and health. The American Society for Nutritional Sciences, 132(12), 3772-3781. https://doi.org/10.1093/jn/132.12.3772.

Hasler, C. e Brown, A. (2009). Position of the American Dietetic Association: Functional Foods. Journal of the American Dietetic Association, 109(4), 735746. https://doi.org/10.1016/j.jada.2009.02.023.

Heil, M., Delsinne, T., Hilpert, A., Schürkens, S., Andary, C., Linsenmair, E. K., Sousa, M. \& McKey, D. (2002). Reduced chemical defence in ant-plants? A critical re-evaluation of a widely accepted hypothesis. Oikos, 99, 457. https://www.uni-due.de/botanik/heil/Heiletal_Oikos2002_tradeoffs_20.pdf

Hidalgo, L. (1993). Tratado de viticulture general. Madrid: Mundi. https://dialnet.unirioja.es/servlet/autor?codigo=521896

Hollman, P. C., Van Tripp, J., Buysman, M. N., Van Der Gaag, M. S., Mengelers, M. J., Vries, J. H. \& M B Katan, M. B. (1995). Relative Bioavailability of the flavonóide quercetin from various foods in man. Federation of European Biochemical Societies leters. 418, 152-156. https://doi.org/10.1016/s00145793(97)01367-7

Jeandet, P., Douillet-Breuil, A. C., Bessis, R. Debord, S., Sbaghi, M. \& Adrian, M. (2002). Phytoalexins from the Vitaceae: biosynthesis, phytoalexin gene expression in transgenic plants, antifungal activity, and metabolismo. J. Agric. Food Chem., 50, 2731-2741. https://doi.org/10.1021/jf011429s

Kerem, Z., Bilkis, I. \& Flaishman, M. A. (2006). Antioxidant activity and inhibition of alphaglucosidase by trans-resveratrol, piceid, and a novel transstilbene from the roots of Israeli Rumex bucephalophorus L. J Agric Food Chem., 54: 1243-1247. https://doi.org/10.1021/jf052436+.

Khanbabaee, K. \& Van Ree, T. (2002). Tannins: Classification and Definition. Natural product reports, 18, 641-649. https://doi.org/ 10.1039/b1010611

Kuhn, G., Lovate, J., Prezotto, O., Rivaldo, O., Mandelli, F. \& Sônego, O. (1996). O cultivo da videira: informações básicas. https://www.infoteca.cnptia.embrapa.br/handle/doc/537229.

Leão, P., Silva, D. \& Bassoi, L. (2009). Fruticultura tropical: espécies regionais e exóticas: Capítulo 22. https://www.bdpa.cnptia.embrapa.br/consulta/busca?b=ad\&id=660650\&biblioteca=CPATSA\&busca=autoria:\%22SAMPAIO,\%20C.\% 22\&qFacets=autoria:\% 22SAMPAIO, \%20C. $\% 22 \&$ sort=\&paginacao=t\&paginaAtual $=1$.

Llobera, A. \& Cañellas, J. (2008). Antioxidant activity and dietary fibre of Prensal Blanc white grape (Vitis vinifera) by-products. Institute of Food Science \& Technology, 43(11), 1953-1959. https://doi.org/10.1111/j.1365-2621.2008.01798.x

López-Miranda, S., Serrano-Martínez, A., Hernández-Sánchez, P., Guardiola, L., Pérez-Sánchez, H., Fortea, I. \& Núñez-Delicado, E. (2016). Use of cyclodextrins to recover catechin and epicatechin from red grape pomace. Food Chemistry, 203, 379-385. https://doi.org/10.1016/j.foodchem.2016.02.100

Losso, F. \& Pereira, R. A vitivinicultura de altitude em Santa Catarina (Brasil): espaços privilegiados para o turismo. (2014). Turismo \& Sociedade, 7(3), 418445. https://revistas.ufpr.br/turismo/article/viewFile/38857/23694.

Machado, H., Nagem, T. J., Peters, V. M., Fonseca, C. S. \& Oliveira, T. T. (2008). Flavonóides e seu potencial terapêutico. Boletim do Centro de Biologia da Reprodução (Descontinuada), 27(1/2), 33-39. https://periodicos.ufjf.br/index.php/boletimcbr/article/view/17024. 
Manach, C., Scalbert, A., Rémésy, C. \& Jiménez, L. (2004). Polyphenols: food sources and bioavailability. American Journal of Clinical Nutrition, 79(5), 727-747. https://doi.org/10.1093/ajcn/79.5.727

Matias, M. L. (2012). Modificações estruturais de compostos polifenólicos glicosilados e modulação das suas actividades antioxidantes. Tese de Doutorado. https://estudogeral.uc.pt/bitstream/10316/25158/1/Margaux\%20Matias.pdf.

Mello, J. C. P. \& Santos, S. C. Taninos. In: Simões, C. M., Schenkel, E. P., Gosmann, G., Mello, J. C. P., Mentz, L. A. \& Petrovick, P.R. (2001). Farmacognosia: da planta ao medicamento. 3 ed. Porto Alegre: Ed.UFGRS/Ed.UFSC. Cap. 24, 517-543.

Mello, J. P. C. \& Santos, S. C. Em Farmacognosia: da planta ao medicamento; Simões, C. M. O. \& Schenckel, E. P., (2001). Ed. UFSC. $3^{\text {a }}$ ed. https://www.scielo.br/j/rbfar/a/C6JRLYGD9Q584JvF3cJpPcp/?format=pdf\&lang=pt

Miele, A. \& Mandelli, F. (2003). Sistemas de condução. In: Kuhn, G. B. (Org.). Uva para processamento: produção. Brasília, DF: Embrapa Informação Tecnológica, 56-65. https://livimagens.sct.embrapa.br/amostras/00073300.pdf

Monteiro, J. M., Albuquerque, U. P., Araújo, E. L. \& Amorim, E. L. C. (2005). Tannis: from chemistry to ecology. Quím. Nova, 28 (5). https://doi.org/10.1590/S0100-40422005000500029

Morales, M., Ros Barcelo, A. \& Pedreno, M. A. (2000). Plant stilbenes: recent advances in their chemistry and biology. Adv. Plant Physiol, 3, 39-70. https://www.researchgate.net/publication/287584309_Plant_stilbenes_Recent_advances_in_their_chemistry_and_biology

Naczk, M. \& Shahidi, F. (2004). Extraction and analysis of phenolics in food. Journal of Chromatography, 95-111. https://doi.org/10.1016/j.chroma.2004.08.059

Nakamura, Y., Tsuji, S. \& Tonogai, Y. (2003). Method for analysis of tannic acid and its metabolites in biological samples: Application to tannic acid metabolism in the rat. Journal of Agricultural and Food Chemistry ,51(1), 331-339. http://pubs.acs.org/doi/pdf/10.1021/jf020847\%2B

Natividade, M. M. P., Corrêa, L. C., Souza, S. V. C., Pereira, G. E. \& Lima, L. C. O. (2013). Simultaneous analysis of 25 phenolic compounds in grape juice for HPLC: Method validation and characterization of São Francisco Valley samples. Microch. J. 110: 665-674.

Natividade, M. M. P., Fante, C. A., Alves, R. S. \& Lima, L. C. (2010). Avaliação das características físico-químicas de sucos de uva integral para comparação com especificações legais. XIX Congresso de pós-graduação da UFLA. http://www.sbpcnet.org.br/livro/lavras/resumos/1494.pdf

Neves, P. D. O. (2015). Importância dos compostos fenólicos dos frutos na promoção da saúde. Dissertação de Mestrado. https://bdigital.ufp.pt/bitstream/10284/5241/1/PPG_15639.pdf

Nied, A. M. (2019). DO campo ao copo: características do suco de uva produzido por uma cooperativa da região do Vale do Rio Tijucas. https://repositorio.ufsc.br/handle/123456789/203198.

Nobre, S. M., Peixoto, J. A. S. \& Monteiro, A. L. (2006). Síntese de trans-estilbenos substituídos via reação de Suzuki de brometos de vinila. Sociedade Brasileira de Química (SBQ). 29a Reunião Anual da Sociedade Brasileira de Química. http://sec.sbq.org.br/cdrom/29ra/programa.pdf

O’byrne, D. J., Deveraj, S., Grundy, S. M. \& Jialal, I. (2002). Comparison of the antioxidant effects of Concord grape juice flavonoids alpha-tocopherol on markers of oxidative stress in healthy adults. American Journal of clinical nutrition, 76 (6), 1367-1374. https://doi.org/10.1093/ajcn/76.6.1367

Ochiai, T. K., Jiar, R., Cai, Y., Yamaguchi, Y. \& Yamamoto, M. (2015). Periodontal diseaseinduced atherosclerosis and oxidative stress. Antioxidants, 4(3), 577-590. https://doi.org/10.3390/antiox4030577.

Oliveira, D. M. \& Bastos, D. H. M. (2011). Biodisponibilidade de Ácidos Fenólicos. Química Nova, 34(6), 1051-1056. https://doi.org/10.1590/S010040422011000600023

Pádua, D. R. L. (2018). Caracterização de compostos bioativos em uva da cultivar isabel precoce (Vitis Labrusca L.) durante o desenvolvimento fisiológico, cultivada no cerrado goiano. Programa de Pós-Graduação em Ciência e Tecnologia de Alimentos. https://files.cercomp.ufg.br/weby/up/71/o/VERS\%C3\%83O_FINAL_-_Dalila_Rayane_de_Lima_P\%C3\%A1dua.pdf

Pala, C. U. \& Toklucu, A. K. (2013.). Effects of UV-C ligth processing on some quality characteristiscs of grape juices. Food an Bioprocess Techonology. 6, 719- 725. https://doi.org/10.1007/s11947-012-0808-7

Pelzer, E., Guardia, T., Osvaldo, A. Juarez \& Guerreiro. (1998). Acute and chronic Acute and chronic antiinflammatory effects of plant flavonoids. Farmaco, 53, 421-424. https://doi.org/10.1016/s0014-827x(98)00046-9

Penter, F. (2006). Efeito do raleio de cachos na qualidade da uva cabernet sauvignon produzida na serra catarinense. Dissertação de Mestrado - UDESC. https://www.udesc.br/arquivos/cav/id_cpmenu/1354/dissertacao_felipe_penter_15676843161477_1354.pdf

Pereira, R. J. \& Graças, M. C. (2012). Metabólitos secundários vegetais e benefícios antioxidantes. Journal of biotechnology and biodiversity, 3(4), 146-152. https://www.todafruta.com.br/wp-content/uploads/2016/09/Metab\%C3\%B3litos-secund\%C3\%A1rios-ARTIGO.pdf.

Ribeiro de Lima, M. T., Waffo-Téguo, P., Teissedre, P. L., Pujolas, A., Vercauteren, J., Cabanis, J. C. \& Mérillon, J. M. (1999). Determination of Stilbenes (trans-Astringin, cis- and trans-Piceid, and cis- and trans-Resveratrol) in Portuguese Wines. J. Agric. Food Chem, 47, 2666-2670. https://doi.org/10.1021/jf9900884

Rizzon, L. A. \& Link, M. (2006). Composição do suco de uva caseiro de diferentes cultivares. Ciência Rural, 36(2), 689-692. https://doi.org/10.1590/S010384782006000200055 
Rocha, W. S., Lopes, R. M., Silva, D. B. D., Vieira, R. F., Silva, J. P. D. \& Agostini-Costa, T. D. S. (2011). Compostos fenólicos totais e taninos condensados em frutas nativas do cerrado. Revista Brasileira de Fruticultura, 33(4), 1215-1221. https://doi.org/10.1590/S0100-29452011000400021

Rockenbach, I. I. (2008). Compostos fenólicos, ácidos graxos e capacidade antioxidante do bagaço da vinificação de uvas tintas (Vitis vinifera e Vitis labrusca). https://repositorio.ufsc.br/xmlui/bitstream/handle/123456789/91153/254768.pdf?sequence=1\&isAllowed.

Roque, V. R., Radünz, M., Alves, P. \& Gandra, E. A. (2017). Atividade antimicrobiana de óleo de semente de uva (Vitis vinifera, L.) Revista da Jornada de Pós-Graduação e Pesquisa-Congrega Urcamp, 640-649. http://revista.urcamp.edu.br/index.php/rcjpgp/article/view/741/439.

Roupe, K. A., Remsberg, C. M., Yáñez, J. A. \& Davies, N. M. (2006). Pharmacometrics of Stilbenes: Seguing Towards the Clinic. Current Clinical Pharmacology, 1, 81-101. https://doi.org/10.2174/157488406775268246

Ruivo, J., Francisco, C., Oliveira, R. \& Figueiras, A. (2015). The main potentialities of resveratrol for drug delivery systems. Brazilian Journal of Pharmaceutical Sciences. 51(3), 499-513. https://doi.org/10.1590/S1984-82502015000300002

Santana, F. (2012). Caracterização físico-química e sensorial de néctares de uva tradicionais e light. Revista da Universidade Vale do Rio Verde. Três Corações, 10(2), 229-238. http://dx.doi.org/10.5892/ruvrv.2012.102.229238

Santos-Buelga, C. \&Scalbert, A. (2000). Proanthocyanidins and tannin-like compounds - nature, occurrence, dietary intake and effects on nutrition and health. Journal of the Science of Food and Agriculture. https://doi.org/10.1002/(SICI)1097-0010(20000515)80:7<1094::AID-JSFA569>3.0.CO;2-1

Santos, L. J., Araújo, M. G. G., Pontes, E. D. S., Viera, V. B. \& Queiroz, M. P. (2020). Elaboração e Avaliação da Capacidade Antioxidante da Geleia de Uva Isabel com Carnaúba. Research, Society and Development, 9(6), e31961936-e31961936. http://dx.doi.org/10.33448/rsd-v9i6.1936.

Santos, M. V. G. (2013). Elaboração de néctar misto de uva e gengibre. Monografia em engenharia de alimentos https://rosario.ufma.br/jspui/bitstream/123456789/98/1/Monografia\%20Mary\%20V\%C3\%A2nia\%20Gon\%C3\%A7alves\%20Santos.pdf

Sautter, C. K., Denardin, S., Alves, A. O., Mallmann, C. A., Penna, N; G. \& Hecktheuer, L. H. (2005). Determinação de resveratrol em sucos de uva no Brasil. Ciênc. Tecnol. Aliment., 25(3), 437-442. https://doi.org/10.1590/S0101-20612005000300008

Schiedeck, G., Miele, A., Barradas, C. I. N. \& Mandelli, F. (1999). Maturação da uva Niágara Rosada cultivada em estufa de plástico e a céu aberto. Ciência Rural, 29(4), 629-633. https://doi.org/10.1590/S0103-84781999000400010

Schwartz, C., Jesus, J., Ramos, F., Mezalira, T., Ferreira, R., Otutumi, L. \& Soares, A. (2020). Compostos Bioativos Do Bagaço De Uva (Vitis Vinífera): Seus Benefícios E Perspectivas Para O Desenvolvimento Sustentável: Capítulo 37. https://www.editoracientifica.org/books/isbn/978-65-87196-25-1. https://doi.org/10.37885/200700653

Shinagawa, F. (2015). Avaliação da composição química de óleos brasileiros de semente de uva (Vitis Vinífera L) e seu efeito sobre parâmetros bioquímicos e inflamatórios em ratos. https://www.teses.usp.br/teses/disponiveis/9/9131/tde-28052015-091051/publico/Fernanda_Branco_Shinagawa_DO_original.pdf

Sikora, E., Cieślik, E. \& Topolska, K. (2008). The sources of natural antioxidants. Acta Scientiarum Polonorum Technologia Alimentaria, 7(1), 5-17. https://www.food.actapol.net/pub/1_1_2008.pdf.

Silva, A. D. F. (2010). Análise de Compostos Fenólicos e Potencial Antioxidante de Amostras Comerciais de Sucos de Uva e Produtos Derivados de Uvas Vinícolas. https://repositorio.ufpb.br/jspui/bitstream/tede/4090/1/arquivototal.pdf.

Silva, J. A. (2018). Identificação de compostos fenólicos, macroantioxidantes e avaliação da atividade antioxidante do bagaço de uva proveniente da indústria de sucos no Vale do rã de Doutorado. https://repositorio.unilab.edu.br/jspui/bitstream/123456789/2003/1/JOILNA\%20ALVES\%20DA\%20SILVA\%20Disserta\%C3\%A7\%C3\%A3o.pdf

Silva, M. L. C., Costa, R. S., Santos A. S. \& Koblitz, M. G. B. (2010). Compostos fenólicos, carotenóides e atividade antioxidante em produtos vegetais. Semina: Ciências Agrárias, 31(3), 669-681. https://www.uel.br/revistas/uel/index.php/semagrarias/article/viewFile/6510/5926.

Singh, C. K., Siddiqui, I. A., Abd, S. E., Mukhtar, H. \& Ahmad, N. (2016). Combination chemoprevention with grape antioxidants. Mol. Nutr. Food Res. 60(6), 1406-1415. https://doi.org/10.1002/mnfr.201500945.

Souza, É. X. N. (2015). Desenvolvimento e avaliação de sistemas lipossomais com bioativos de uva (Vitis vinifera) para Medicamentos e Cosméticos. https://repositorio.ufba.br/ri/bitstream/ri/24310/1/Disserta\%C3\%A7\%C3\%A3o\%20Final\%20-\%20\%C3\%88rcia\%20Xavier.pdf.

Souza, A. V., Vieira, M. R. S. \& Putti, F. F. (2018). Correlações entre compostos fenólicos e atividade antioxidante em casca e polpa de variedades de uva de mesa. Brazilian Journal of Food Technology, 21. https://doi.org/10.1590/1981-6723.10317

Souza, N. F. V., Soccol, M. C. H. \& Ide, G. M. (2009). Compostos fenólicos em vinhos e seus efeitos antioxidantes na prevenção de doenças. Revista de ciências agroveterinárias, 8(1), 71-83. https://revistas.udesc.br/index.php/agroveterinaria/article/view/5316/3522.

Soares, S. E. (2002). Ácidos fenólicos como antioxidantes. Revista de nutrição, 15(1), 71-81. https://www.scielo.br/j/rn/a/mZxTyVMspZY9WJgC7SSFnbh/?lang=pt\&format=pdf.

Trošt, K., Klančnik, A., Vodopivec, B. M., Lemut, M. S., Novšak, K. J. Peter Raspor, P. \& Možina, S. S. (2016). Polyphenol, antioxidant and antimicrobial potential of six different white and red wine grape processing leftovers. Journal of the science of food and agriculture, 96(14), 4809-4820. https://doi.org/10.1002/jsfa.7981

Trueba, G. T. (2003). Los flavonoides: antioxidantes o prooxidantes. Revista Cubana de Investigaciones Biomédicas, 22, (1). http://scielo.sld.cu/scielo.php?script=sci_arttext\&pid=S0864-03002003000100007. 
Research, Society and Development, v. 10, n. 14, e281101421825, 2021

(CC BY 4.0) | ISSN 2525-3409 | DOI: http://dx.doi.org/10.33448/rsd-v10i14.21825

Unusan, N. (2020). Proanthocyanidins in grape seeds: An updated review of their health benefits and potential uses in the food industry. Journal of Functional Foods, 67. https://doi.org/10.1016/j.jff.2020.103861

Vieira, A., Garcia, J. \& Bruch, K. (2015). Análise exploratória dos potenciais efeitos das mudanças climáticas nos "Vales Da Uva Goethe". Ambiente \& Sociedade, $X V I I I(3), 171-192$. https://www.scielo.br/pdf/asoc/v18n3/1809-4422-asoc-18-03-00171.pdf.

Walle, T., Hsieh, F. \& DeLegge, M. H. (2006). High Absorption but very Low Bioavailability of Oral Resveratrol in Humans. Drug Metabolism and Disposition. The American Society for Pharmacology and Experimental Therapeutics, 32(12), 1377-1382. https://doi.org/10.1124/dmd.104.000885.

Xia, E. Q., Fang, D. G., Jun, G. Y. \& Bin, L. H. (2010). Biological activities of polyphenols from grapes. International. J. Molec. Scien. 11(2), 622646. https://doi.org/ 10.3390/ijms11020622.

Yao, L. H., Jian, Y. M., Shi, J., Tomás-Barberán, F. A., Datta, N., Singanusong, R. \& Chen, S. S. (2004). Flavonoids in Food and Their Health Benefits. Plant Foods for Human Nutrition, 59, 113-122. https://link.springer.com/article/10.1007/s11130-004-0049-7

Yilmaz, Y. \& Toledo, R. (2004). Health aspects of functional grape seed constituents. Trends in Food Science \& Technology, 15, 422-433. https://doi.org/10.1016/j.tifs.2004.04.006.

Yoo, Y., Saliba A. \& Prenzler P. (2010). "Should red wine be considered a functional food?" Comprehensive reviews in food science and food safety, 9(5), 530-551. http://dx.doi.org/10.1111/J.1541-4337.2010.00125.X 